\title{
Tumour associated lymphocytes in the pleural effusions of patients with mesothelioma express high levels of inhibitory receptors
}

\author{
Jonathan Chee ${ }^{1^{*}} \mathbb{0}$, Mark W. Watson², Abha Chopra², Bella Nguyen ${ }^{3}$, Alistair M. Cook', Jenette Creaney ${ }^{1}$, \\ Willem J. Lesterhuis ${ }^{1}$, Bruce W. Robinson ${ }^{1,4}$, Y. C. Gary Lee ${ }^{4,5}$, Anna K. Nowak ${ }^{1,3}$, Richard A. Lake ${ }^{1}$ \\ and Alison M. McDonnell ${ }^{1}$
}

\begin{abstract}
Objective: Pleural effusion (PE) is a common feature of malignant pleural mesothelioma. These effusions typically contain lymphocytes and malignant cells. We postulated that the PE would be a source of lymphocytes for analysis of tumor immune milieu. The aim of this study was to compare the phenotype and T cell receptor usage of pleural effusion T cells with paired concurrently drawn peripheral blood lymphocytes. We used multi-parameter flow cytometry and high-throughput T cell receptor sequencing to analyse peripheral blood and pleural effusion mononuclear cells.

Results: Both $\mathrm{CD}^{+}$and $\mathrm{CD}^{+}{ }^{+} \mathrm{T}$ cells from effusion showed increased expression of T cell inhibitory receptors PD-1, LAG-3 and Tim-3 compared to blood. Comprehensive T cell receptor sequencing on one of the patients showed a discordant distribution of clonotypes in the antigen-experienced $\left(\mathrm{PD}-1^{+}\right)$compartment between effusion and blood, suggesting an enrichment of antigen specific clonotypes in the effusion, with potential as an immunological response biomarker.
\end{abstract}

Keywords: Mesothelioma, Pleural effusion, T cell receptor

\section{Introduction}

Malignant mesothelioma originates from mesothelial cells lining the pleura. Most patients have a history of asbestos exposure, present with advanced disease and receive palliative chemotherapy only. The median survival for patients treated with cisplatin and pemetrexed is around 12 months [1] and most patients die from their disease.

The success of immunotherapy targeting checkpoint inhibitory $\mathrm{T}$ cell receptors in a variety of cancer types, has seen the anti-tumour immune response re-emerge as a promising prognostic marker, therapeutic target and a

\footnotetext{
*Correspondence: jonathan.chee@uwa.edu.au

${ }^{1}$ National Centre for Asbestos Related Diseases, School of Medicine and Pharmacology, University of Western Australia, Nedlands, Western Australia, Australia

Full list of author information is available at the end of the article
}

potential biomarker of response for cancer immunotherapy [2]. Such therapies are under clinical investigation for the treatment of patients with mesothelioma [3], and understanding $\mathrm{T}$ cell responses in these patients is crucial for improving the efficacy of immunotherapy.

The prognostic significance of tumour infiltrating lymphocytes (TILs) is established for many cancer types including mesothelioma [4]. Longitudinal characterisation of $\mathrm{T}$ cell phenotype and $\mathrm{T}$ cell receptor (TCR) usage at the tumour site could help us to understand how to promote effective anti-tumour immunity. However, serial analysis of immune changes at the tumour site is rarely feasible in clinical practice as tumour biopsies are invasive. Malignant pleural effusions (PE), a recurrent and common complication of mesothelioma, are regularly drained as a palliative measure and can be sampled serially [5]. PE is an abnormal accumulation of fluid in 
the pleural space with $\mathrm{T}$ lymphocytes the predominant immune cells [6]. Given that malignant PE are intimately associated with mesothelioma, they form an important part of the local tumour environment and as such, immune events in the PE may serve as surrogate markers of the intratumoural milieu. We characterized $\mathrm{T}$ cell phenotype in PE and peripheral blood in 9 patients with mesothelioma, and compared the $\mathrm{T}$ cell repertoire between $\mathrm{PE}$ and peripheral blood of a selected patient.

\section{Main text}

\section{Materials and methods}

\section{Sample collection and processing}

This study was approved by the site Human Research Ethics Committee and the patient provided written informed consent for collection and analysis of biological samples. Blood was collected into a heparinized Vacutainer $^{\circledR}$ (BD Diagnostics) and peripheral blood mononuclear cells (PBMC) isolated according to manufacturer's instructions. A $50 \mathrm{ml}$ PE sample was collected. Ficoll density centrifugation was used to isolate PE mononuclear cells (PEMC). Cells were stored in liquid nitrogen until analysis.

The nine participants in the current study had a histologically or cytologically confirmed diagnosis of malignant pleural mesothelioma. Participants could have any stage or duration of disease; prior treatment with chemotherapy or radiotherapy was allowed. Effusions from patients with prior talc pleurodesis or pleural infection were excluded from this study.

\section{Flow cytometry}

Thawed cells were labelled with antibodies: CD14-APCeFluor ${ }^{\circledR} 780$ (61D3), CD19-APC-eFluor ${ }^{\circledR} 780$ (HIB19), LAG-3-PE (3DS223H) (eBioscience); CD45-BUV395
(HI30), CD3-BV510 (UCHT1), CD4-BV711 (OKT4), CD8a-FITC (RPA-T8), PD-1-PerCP-Cy5.5 (EH12.2H7), PD-1-PECy7 (EH12.2H7), Tim-3-APC (F38-232), CD45RA-BV785 (HI100) (BioLegend). Dead cells were excluded using Viability Dye eFluor ${ }^{\mathrm{TM}} 780$ (ThermoFisher). Samples were acquired on a LSR Fortessa (BD Biosciences) and analyzed using FlowJov10 (Treestar).

\section{TCR sequencing}

Cells were sorted on CD3, CD4, CD8 and PD-1 expression with a $\mathrm{BD}$ Influx $^{\mathrm{TM}}$ (BD Biosciences). DNA was extracted from sorted cells using QIAmp DNA Kit (Qiagen). DNA sequences were amplified with a Human TCR $\beta$ ImmunoSeq Kit (Adaptive Biotechnologies). Sequencing was performed on a MiSeq (MS-102-3001, Illumina) and data was analyzed using the Adaptive ImmunoSeq suite. Each TCR clonotype is defined as a unique TCR $\beta$ nucleotide sequence. Differential abundance of $\mathrm{T}$ cell clones were compared as previously described [7]. The diversity of each sample was assigned a clonality score [8], whereby each score varied from 0 (each clone appearing once) to 1 (monoclonal sample).

\section{Results \\ Malignant effusions have proportionately more T cells that express inhibitory receptors, compared to blood}

Pleural effusion mononuclear cells (PEMC) were contemporaneously collected with peripheral blood mononuclear cells (PBMC) from 9 male patients with pleural mesothelioma. Patient characteristics are shown in Table 1. Biological samples were analyzed by multiparameter flow cytometry. The $\mathrm{CD}^{+} \mathrm{T}$ cell component of both PE and peripheral blood demonstrated similar proportions of the $\mathrm{CD}^{+}$and $\mathrm{CD}_{4}^{+}$subsets (blood vs.

Table 1 Patient characteristics at the point when effusion and blood samples were taken

\begin{tabular}{|c|c|c|c|c|c|c|c|}
\hline Patient no. & $\begin{array}{l}\text { Age (at } \\
\text { sample } \\
\text { date) }\end{array}$ & $\begin{array}{l}\text { Sample time } \\
\text { from diagnosis } \\
\text { (days) }\end{array}$ & Histology & Prior treatment & $\begin{array}{l}\text { Indwelling pleural } \\
\text { catheter (IPC)/ } \\
\text { thoracentesis }\end{array}$ & Effusion vol. (ml) & $\begin{array}{l}\text { Cell concentration } \\
\text { in effusion } \\
\left(\times 10^{7} / 100 \mathrm{ml}\right)\end{array}$ \\
\hline 1 & 76 & 335 & Epithelioid & No & IPC & 1050 & 3.60 \\
\hline 2 & 66 & 145 & Epithelioid & No & Thoracentesis & 535 & 8.47 \\
\hline 3 & 80 & 403 & Epithelioid & $\begin{array}{l}\text { Carboplatin/pem- } \\
\text { etrexed }\end{array}$ & Thoracentesis & 200 & 3.02 \\
\hline 4 & 61 & 705 & Epithelioid & No & IPC & 700 & 9.00 \\
\hline 5 & 58 & 250 & Epithelioid & $\begin{array}{l}\text { Cisplatin/pem- } \\
\text { etrexed }\end{array}$ & IPC & 300 & 2.16 \\
\hline 6 & 59 & 50 & Epithelioid & No & Thoracentesis & 950 & 3.90 \\
\hline 7 & 76 & 14 & Not specified & No & IPC & 1450 & 2.21 \\
\hline 8 & 68 & 68 & Epithelioid & No & Thoracentesis & 1080 & 2.22 \\
\hline *9 & 72 & 389 & Not specified & No & IPC & 120 & 2.99 \\
\hline
\end{tabular}

*Patient samples underwent $\mathrm{T}$ cell receptor sequencing 
effusion, $\mathrm{CD}^{+}{ }^{+} \mathrm{T}$ cells: $71.9 \% \pm 10.1 \%$ vs. $70.3 \% \pm 12.5 \%$; $\mathrm{CD}^{+}$T cells: $22.2 \% \pm 9.7 \%$ vs. $23.3 \% \pm 9.6 \%$ ).

$\mathrm{T}$ cells within the tumour environment can display a dysfunctional phenotype characterized by expression of $\mathrm{T}$ cell inhibitory receptors [9]. Therefore we compared the cell surface expression of PD-1, LAG-3 and Tim-3 on $\mathrm{T}$ cells in peripheral blood and PE. In the $\mathrm{CD} 4^{+} \mathrm{T}$ cell population, there was a statistically significant larger proportion of PE $\mathrm{T}$ cells that expressed PD-1 $(\mathrm{p}=0.004)$, Tim-3 $(\mathrm{p}=0.004)$ and LAG-3 $(\mathrm{p}=0.004)$ compared to peripheral blood (Fig. 1a). The proportion of $\mathrm{CD} 8^{+} \mathrm{T}$ cells expressing PD-1 $(\mathrm{p}=0.004)$ and LAG-3 $(\mathrm{p}=0.01)$ was also significantly higher in the PE compared with peripheral blood (Fig. 1a). Overall, the proportion of $\mathrm{CD}^{+}$and $\mathrm{CD}^{+}{ }^{+} \mathrm{T}$ cells expressing PD- 1 in PE was fivefold higher than $\mathrm{T}$ cells in peripheral blood, with PD-1 being the inhibitory receptor most overexpressed in $\mathrm{PE}$ $\mathrm{T}$ cell subsets compared with Tim-3 $\left(\mathrm{CD} 4^{+} \mathrm{p}=0.004\right.$, $\left.\mathrm{CD}^{+} \mathrm{p}=0.0001\right)$ and LAG-3 $\left(\mathrm{CD}^{+} \mathrm{p}=0.002, \mathrm{CD} 8^{+}\right.$ $\mathrm{p}=0.04)$ (Fig. 1b).

\section{Malignant effusions have diverse TCR repertoires compared to blood}

We examined the $\mathrm{T}$ cell repertoire by sequencing the TCR $\beta$ chain in T cells from PE and matched peripheral blood. As PD-1 was the most abundantly expressed $\mathrm{T}$ cell inhibitory receptor in our PE samples compared with blood, $\mathrm{T}$ cell subsets were further sorted into $\mathrm{CD} 4^{+} \mathrm{PD}-1^{+}$and $\mathrm{CD} 8^{+} \mathrm{PD}-1^{+}$populations. We performed high throughput TCRseq in $\mathrm{CD} 4^{+}, \mathrm{CD} 4^{+} \mathrm{PD}-1^{+}$, $\mathrm{CD}^{+}$and $\mathrm{CD} 8^{+} \mathrm{PD}-1^{+} \mathrm{T}$ cells derived from matched PE and peripheral blood. This was performed in a single participant (patient 9 in Table 1), who had no prior treatment that might alter the TCR repertoire, and was selected on the basis of sample availability.

$\mathrm{CD}_{4}{ }^{+} \mathrm{T}$ cells in $\mathrm{PE}$ and $\mathrm{PB}$ demonstrated receptor diverse populations (Clonality<0.02) (Fig. 2a). $\mathrm{CD}^{+} \mathrm{T}$ cells in blood had a higher clonality score compared to the PE, suggesting expansion of specific TCR clonotypes in the blood (Fig. 2a). A single dominant TCR clone comprised $27.6 \%$ of total $\mathrm{CD} 8^{+} \mathrm{T}$ cells in $\mathrm{PB}$, but only $1.4 \%$ of effusion $\mathrm{CD}^{+} \mathrm{T}$ cells. Both blood and PE contained distinct $\mathrm{CD} 8^{+} \mathrm{T}$ cell clonotypes that differentially populated one compartment or the other (Fig. 2b). There were fewer differentially expressed $\mathrm{CD} 4^{+}$clonotypes (Fig. 2c).

When we examined the PD- $1^{+}$subsets, the clonality scores in the blood were similarly higher than the effusion (Fig. 2d). The number of differentially expressed CD8 ${ }^{+} \mathrm{PD}-1^{+}$clones in each compartment were similar to the $\mathrm{CD}^{+}$analysis (Fig. 2e). Interestingly, the highly dominant $\mathrm{CD}^{+} \mathrm{T}$ cell clone in this patient's blood was not present in the $\mathrm{CD} 8^{+} \mathrm{PD}-1^{+} \mathrm{PBMCs}$, suggesting this patient had an antecedent infection independent of the pleural space. Importantly, the number of differentially expressed $\mathrm{CD}^{+} \mathrm{T}$ cell clones in each compartment was higher in the $\mathrm{CD} 4^{+} \mathrm{PD}-1^{+}$analysis compared to the $\mathrm{CD}^{+}$analysis (27 vs. 3; Fig. 2f). There were marked clonotypic expansions in $\mathrm{CD} 4^{+} \mathrm{PD}-1^{+}$population that were not evident in the bulk $\mathrm{CD} 4^{+}$population, showing that some differences were only observed after fine analysis of clonal frequency associated with phenotype.

\section{Discussion}

Tumour biopsies from patients with mesothelioma are difficult to obtain, can cause significant morbidity, and are usually only taken once at diagnosis unless a subsequent surgical resection is performed. Thus, serial collection of malignant PE provides a unique opportunity to analyze dynamic events adjacent to the tumour microenvironment over time. A recent study by Aaerts et al. showed that the cellular composition of malignant $\mathrm{PE}$ over time is dynamic and influenced by response to treatment [10]. While this study was limited to a small group of patients, ongoing longitudinal studies will determine if PE T cells behave similarly to TILs and peripheral blood lymphocytes during disease progression and immunotherapy. Our data suggest that PE T cells, like TILs, exhibit an exhausted phenotype characterized by increased expression of inhibitory markers as compared with peripheral blood $\mathrm{T}$ cells. In line with this, previous studies have demonstrated increased expression of PD- 1 and Tim- 3 on $\mathrm{CD}^{+}$and $\mathrm{CD} 8^{+} \mathrm{T}^{-}$cells in PE compared with matched blood in patients with mesothelioma $[11,12]$ and lung cancer [13-15], suggesting that $\mathrm{T}$ cells in the PE more closely approximate TILs than do T cells in peripheral blood. Of note, the expression of coinhibitory markers on TILs has been shown to correlate with response to immunotherapy [16], supporting the potential for PE T cells to provide predictive information longitudinally.

We examined the $\mathrm{T}$ cell repertoire from $\mathrm{PE}$ and blood in a single patient using TCRseq. $\mathrm{CD} 4^{+}$and $\mathrm{CD} 8^{+} \mathrm{TCR}$ repertoires were diverse in the $\mathrm{PE}$, suggesting minimal $T$ cell expansion in the PE of this patient. This contrasts oligoclonal $\mathrm{T}$ cell expansion observed in ascites derived from patients with ovarian cancer [17]. We observed a more restricted TCR repertoire in effusion $\mathrm{CD} 4^{+} \mathrm{PD}-1^{+}$ $\mathrm{T}$ cells compared to $\mathrm{CD} 4^{+} \mathrm{T}$ cells, similar to previous studies studying PD-1 $1^{+}$TILs $[9,18]$. In depth analysis of $\mathrm{CD} 4^{+} \mathrm{PD}-1^{+} \mathrm{T}$ cells also uncovered more differentially expressed TCR clones in the effusion, suggesting that focusing on PD- $1^{+} \mathrm{T}$ cells might yield important insight into the immunological milieu.

$\mathrm{PD}-1^{+} \mathrm{T}$ cells is a population of interest to understand the relationship between $\mathrm{T}$ cells in the peripheral blood, PE and tumour. As we reported the findings 
a

PD-1
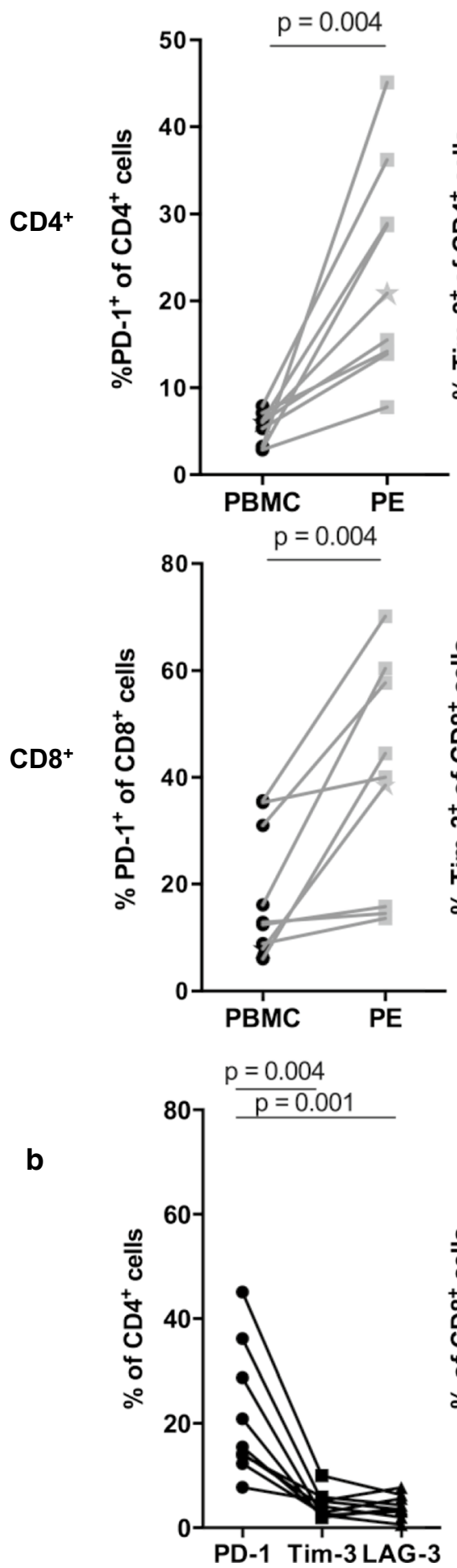

Tim-3

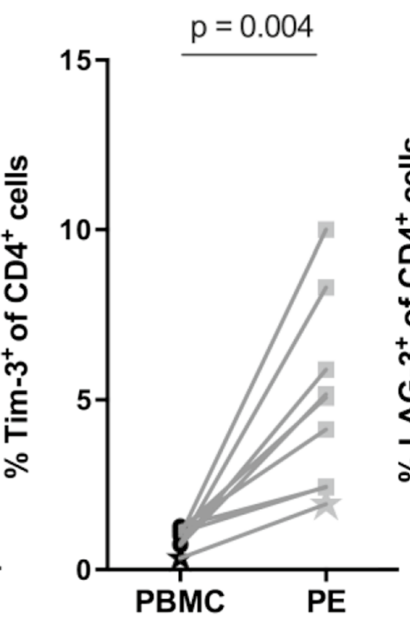

$p=0.164$
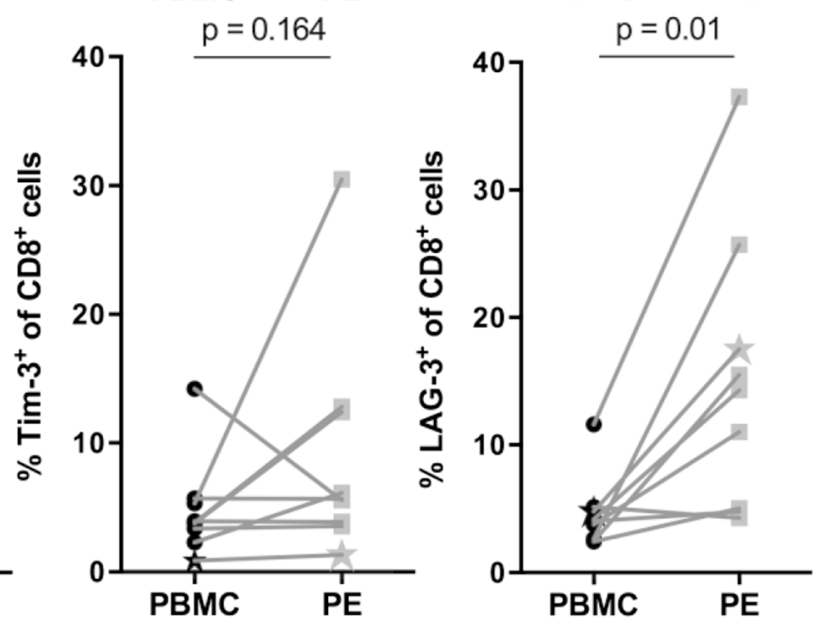

LAG-3
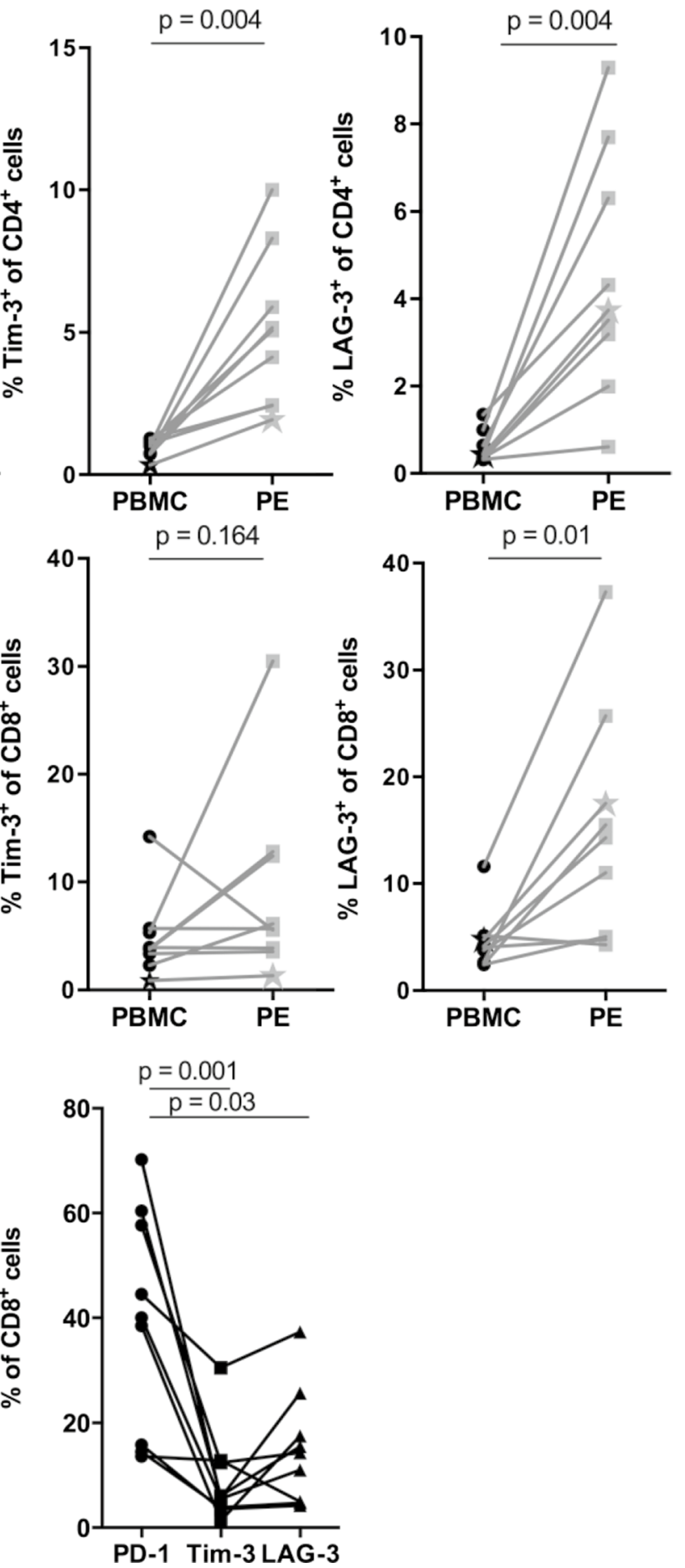

Fig. 1 Frequency of inhibitory receptor expressing T cells in matched blood and effusion samples from malignant mesothelioma patients. a PD-1, Tim-3 and LAG-3 expressing CD4 $4^{+}$(top row) and $\mathrm{CD} 8^{+}$(bottom row) T cells plotted as a frequency of total $\mathrm{CD}_{3}{ }^{+} \mathrm{CD} 4^{+}$or $\mathrm{CD}_{3}^{+} \mathrm{CD} 8^{+} \mathrm{T}$ cells respectively. Each point and connecting line represents a paired patient sample, and the star on each graph represents the single patient sample that underwent TCR sequencing. All paired samples were compared using a Wilcoxon's test. b Frequency of PD-1, Tim-3 and LAG-3 expressing CD4 ${ }^{+}$ and $\mathrm{CD} 8^{+} \mathrm{T}$ cells from effusion samples. Matched samples were compared with a Friedman test, corrected for multiple comparisons using Dunn's test 


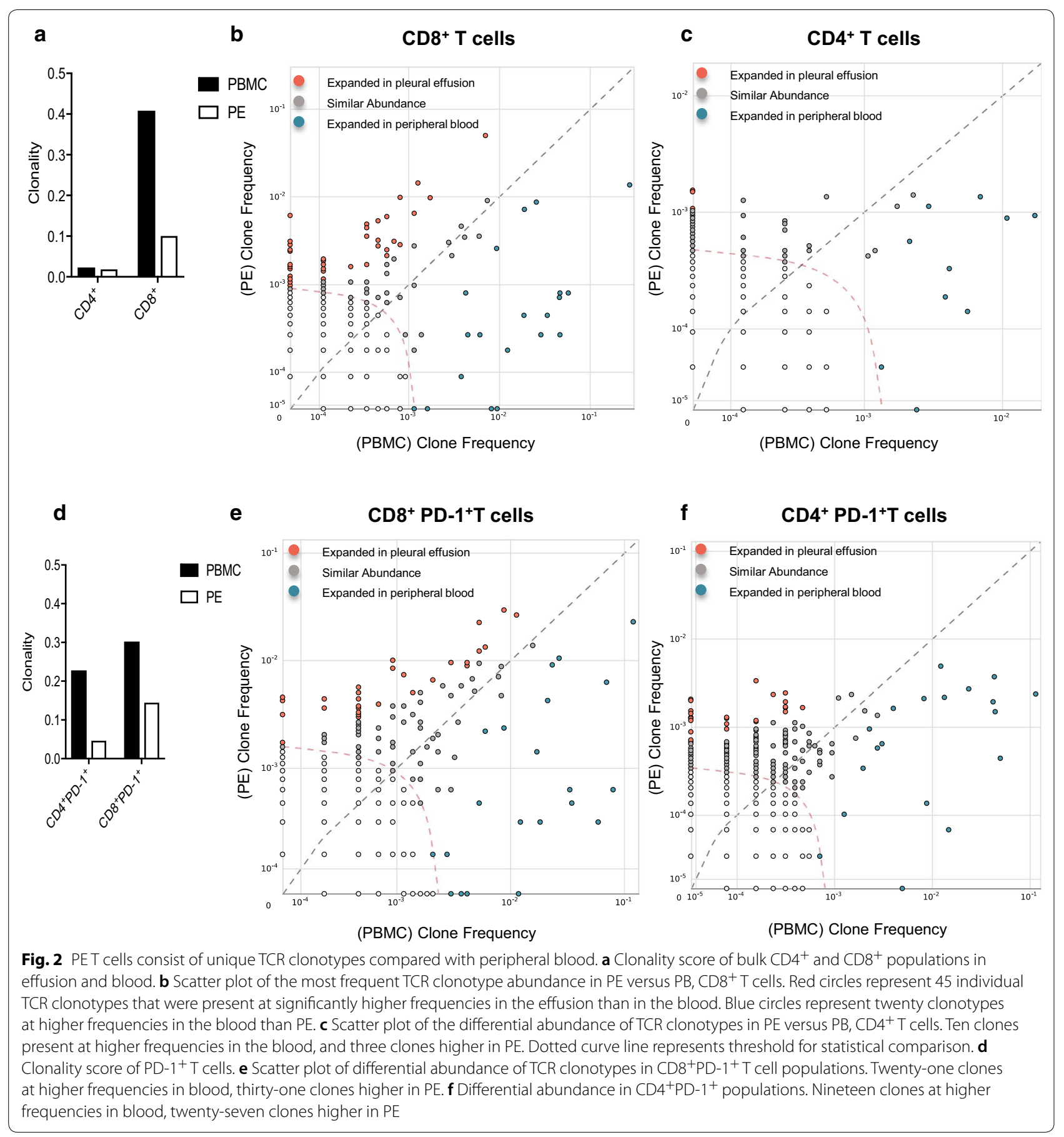

from a single patient, it remains to be seen if TCR repertoire in the PE is equally diverse in other patients with mesothelioma, or if the repertoire changes after different therapies. The specificity of $\mathrm{T}$ cells in the effusion is still to be determined, as is their ability to recognize tumour antigens.

\section{Limitations}

The study was limited by small patient numbers, especially with one patient for the TCR analysis. Tumour biopsies were unavailable for a comprehensive comparison of inhibitory receptor expression and TCR diversity between all compartments. 


\section{Authors' contributions}

JCh and AM performed experiments, wrote, and edited the main manuscript text. AM, ACo, JC, MW, ACh prepared figures. BN collected human samples. $J C, W L, B R, Y L$ provided intellectual input into manuscript. AN, RL and AM provided input into study design and experimental setup. All authors read and approved the final manuscript.

\section{Author details}

${ }^{1}$ National Centre for Asbestos Related Diseases, School of Medicine and Pharmacology, University of Western Australia, Nedlands, Western Australia, Australia. ${ }^{2}$ Institute for Immunology and Infectious Diseases, Murdoch University, Murdoch, Australia. ${ }^{3}$ Department of Medical Oncology, Sir Charles Gairdner Hospital, Nedlands, Western Australia, Australia. ${ }^{4}$ Department of Respiratory Medicine, Sir Charles Gairdner Hospital, Nedlands, Western Australia, Australia. ${ }^{5}$ Institute of Respiratory Health, School of Medicine, University of Western Australia, Sir Charles Gairdner Hospital, Nedlands, Western Australia, Australia.

\section{Acknowledgements}

We acknowledge the facilities, and the scientific and technical assistance of the Australian Microscopy \& Microanalysis Research Facility at the Centre for Microscopy, Characterisation \& Analysis University of Western Australia, a facility funded by the University, State and Commonwealth Governments. The authors also acknowledge Justin Leon and Cynthia Gregory for sample collection and processing

\section{Competing interests}

The authors declare that they have no competing interests.

\section{Consent for publication}

Not applicable.

\section{Availability of data and materials}

The datasets used and/or analysed during the current study are available from the corresponding author on reasonable request.

\section{Ethics approval and consent to participate}

This study was approved by the Sir Charles Gairdner Hospital Human Research Ethics Committee and the patient provided written informed consent for collection and analysis of biological samples.

\section{Funding}

We acknowledge funding from Cancer Council Western Australia, Raine Foundation, University of Western Australia, US Department of Defence, the Australian Science and Industry Endowment Fund, Insurance Commission of Western Australia and the National Health and Medical Research Council.

\section{Publisher's Note}

Springer Nature remains neutral with regard to jurisdictional claims in published maps and institutional affiliations.

Received: 29 October 2018 Accepted: 26 November 2018 Published online: 05 December 2018

\section{References}

1. Kondola S, Manners D, Nowak AK. Malignant pleural mesothelioma: an update on diagnosis and treatment options. Ther Adv Respir Dis. 2016;10(3):275-88.

2. Lesterhuis WJ, Bosco A, Millward MJ, Small M, Nowak AK, Lake RA. Dynamic versus static biomarkers in cancer immune checkpoint blockade: unravelling complexity. Nat Rev Drug Discov. 2017;16:264-74.
3. McDonnell AM, Cook A, Robinson BWS, Lake RA, Nowak AK. Serial immunomonitoring of cancer patients receiving combined antagonistic anti-CD40 and chemotherapy reveals consistent and cyclical modulation of T cell and dendritic cell parameters. BMC Cancer. 2017;17(1):417.

4. Yamada N, Oizumi S, Kikuchi E, Shinagawa N, Konishi-Sakakibara J, Ishimine A, Aoe K, Gemba K, Kishimoto T, Torigoe T, et al. CD8 ${ }^{+}$tumorinfiltrating lymphocytes predict favorable prognosis in malignant pleural mesothelioma after resection. Cancer Immunol Immunother. 2010:59(10):1543-9.

5. West SD, Lee YC. Management of malignant pleural mesothelioma. Clin Chest Med. 2006;27(2):335-54.

6. Scherpereel A, Grigoriu BD, Noppen M, Gey T, Chahine B, Baldacci S, Trauet J, Copin MC, Dessaint JP, Porte H, et al. Defect in recruiting effector memory $\mathrm{CD}^{+}{ }^{+}$-cells in malignant pleural effusions compared to normal pleural fluid. BMC Cancer. 2013;13:324.

7. DeWitt WS, Emerson RO, Lindau P, Vignali M, Snyder TM, Desmarais C, Sanders C, Utsugi H, Warren EH, McElrath J, et al. Dynamics of the cytotoxic $T$ cell response to a model of acute viral infection. J Virol. 2015;89(8):4517-26.

8. Stewart JJ, Lee CY, Ibrahim S, Watts P, Shlomchik M, Weigert M, Litwin S. A Shannon entropy analysis of immunoglobulin and T cell receptor. Mol Immunol. 1997;34(15):1067-82.

9. Gros A, Robbins PF, Yao X, Li YF, Turcotte S, Tran E, Wunderlich JR, Mixon A, Farid S, Dudley ME, et al. PD-1 identifies the patient-specific CD8(+) tumor-reactive repertoire infiltrating human tumors. J Clin Investig. 2014;124(5):2246-59.

10. Lievense LA, Bezemer K, Cornelissen R, Kaijen-Lambers ME, Hegmans $J P$, Aerts JG. Precision immunotherapy; dynamics in the cellular profile of pleural effusions in malignant mesothelioma patients. Lung cancer. 2016;107:36-40.

11. Khanna S, Thomas A, Abate-Daga D, Zhang J, Morrow B, Steinberg SM, Orlandi A, Ferroni P, Schlom J, Guadagni F, et al. Malignant mesothelioma effusions are infiltrated by $\mathrm{CD}^{+} \mathrm{T}$ cells highly expressing PD-L1 and the $\mathrm{PD}-\mathrm{L} 1^{+}$tumor cells within these effusions are susceptible to ADCC by the anti-PD-L1 antibody avelumab. J Thorac Oncol. 2016;11(11):1993-2005.

12. Marcq E, Waele J, Audenaerde JV, Lion E, Santermans E, Hens N, Pauwels $P$, van Meerbeeck JP, Smits ELJ. Abundant expression of TIM-3, LAG-3, PD-1 and PD-L1 as immunotherapy checkpoint targets in effusions of mesothelioma patients. Oncotarget. 2017;8(52):89722-35.

13. Li L, Yang L, Wang L, Wang F, Zhang Z, Li J, Yue D, Chen X, Ping Y, Huang $L$, et al. Impaired $T$ cell function in malignant pleural effusion is caused by TGF-beta derived predominantly from macrophages. Int J Cancer. 2016;139(10):2261-9.

14. Koyama S, Akbay EA, Li YY, Herter-Sprie GS, Buczkowski KA, Richards WG, Gandhi L, Redig AJ, Rodig SJ, Asahina H, et al. Adaptive resistance to therapeutic PD-1 blockade is associated with upregulation of alternative immune checkpoints. Nat Commun. 2016;7:10501.

15. Hu CY, Zhang YH, Wang T, Chen L, Gong ZH, Wan YS, Li QJ, Li YS, Zhu B. Interleukin-2 reverses CD8(+) T cell exhaustion in clinical malignant pleural effusion of lung cancer. Clin Exp Immunol. 2016;186(1):106-14.

16. Tumeh PC, Harview CL, Yearley JH, Shintaku IP, Taylor EJ, Robert L, Chmielowski B, Spasic M, Henry G, Ciobanu V, et al. PD-1 blockade induces responses by inhibiting adaptive immune resistance. Nature. 2014;515(7528):568-71.

17. Jang M, Yew PY, Hasegawa K, Ikeda Y, Fujiwara K, Fleming GF, Nakamura Y, Park JH. Characterization of T cell repertoire of blood, tumor, and ascites in ovarian cancer patients using next generation sequencing. Oncoimmunology. 2015;4(11):e1030561.

18. Pasetto A, Alena G, Robbins PF, Deniger DC, Prickett TD, Matus-Nicodemos R, Douek DC, Howie B, Robins H, Parkhurst MR, et al. Tumor- and neoantigen-reactive $T$-cell receptors can be identified based on their frequency in fresh tumor. Cancer Immunol Res. 2016;4:734-43. 